\title{
Primary Pulmonary Synovial Sarcoma during Pregnancy: A Diagnostic and Therapeutic Dilemma
}

\author{
Eric M. Harris Robert W. Allan Charles E. Riggs Jr \\ Division of Hematology and Oncology, Department of Medicine, College of Medicine, \\ University of Florida, Gainesville, Fla., USA
}

\section{Key Words}

Primary pulmonary synovial sarcoma $\cdot$ Pregnancy $\cdot$ Ifosfamide

\begin{abstract}
Synovial sarcoma is a rare soft tissue sarcoma that typically arises in the extremities of young adults. We report a case of a 26-year-old pregnant woman with biopsy-proven primary synovial sarcoma of the lung that was treated with chemotherapy with radiographic response. This is only the third documented case of primary pulmonary synovial sarcoma occurring during pregnancy and the first case where chemotherapy was given.
\end{abstract}

(C) 2014 S. Karger AG, Basel

\section{Introduction}

Synovial sarcoma is a rare soft tissue sarcoma accounting for approximately $8 \%$ of the soft tissue sarcomas [1]. It is a mesenchymal tumor with varied epithelial differentiation and is frequently associated with a translocation between chromosomes $\mathrm{X}$ and 18 . Though synovial sarcoma predominantly affects the extremities of young adults, primary lesions have also been identified in the head and neck, abdominal wall, and thorax (including the mediastinum, pericardium, pleura, and lung) [2-4]. A recent Medline search revealed approximately 60 cases of primary pulmonary synovial sarcoma reported worldwide in the last 30 years. Only 2 of these cases were reported during pregnancy [5, 6].

We report the case of a female patient with primary pulmonary synovial sarcoma diagnosed and treated with neoadjuvant chemotherapy during pregnancy. 
Harris et al.: Primary Pulmonary Synovial Sarcoma during Pregnancy: A Diagnostic and Therapeutic Dilemma

\section{Case Presentation}

A 26-year-old Caucasian female, G2P1, at 21 weeks' gestation with no other significant medical history presented to a community hospital with a dry cough and right-sided pleuritic chest pain, which radiated to her right shoulder. She reported no family history of unusual or early-onset malignancies, she never smoked and she worked as a receptionist at a wastewater management company. Her previous pregnancy 2 years ago was uncomplicated and resulted in a healthy baby boy.

On presentation, the patient was afebrile, tachypneic, and tachycardic with normal pulse oximetry. Physical examination was remarkable for diminished lung sounds at the right base. Her complete blood count was remarkable only for a low-grade normocytic anemia and her comprehensive metabolic panel was normal. Her symptoms and pregnancyassociated risk were suggestive of a pulmonary embolus, which prompted a CT of the chest with IV contrast. The CT scan revealed a smooth, lobulated $6.5-\mathrm{cm}$ mass in the right hilum (fig. 1). No parenchymal disease or pulmonary emboli were appreciated. She was referred to our academic center for further evaluation and treatment considerations.

One week after her initial presentation, the patient underwent bronchoscopy, which disclosed a mass arising in the airway. Multiple transbronchial needle aspirations and forceps biopsies were performed.

H\&E staining of the biopsied specimens revealed malignant spindle cells infiltrating endobronchial tissue (fig. 2a). Immunohistochemistry was positive for CD99 and Bcl-2, but negative for CD34 (fig. 2b-d). Additional stains for epithelial membrane antigen pancytokeratin AE1/3, Cam5.2, desmin, smooth muscle actin, S-100, and HMB45 were all negative.

Fluorescence in situ hybridization performed on the formalin-fixed paraffin embedded tissue revealed two populations: a predominant population (>90\%) of polypoid cells with multiple copies of SYT probe of which $>80 \%$ had the break-apart signal and a small population (10\%) of diploid cells showing the break-apart signal for SYT probe. The combined histopathology, immunohistochemistry, and fluorescence in situ hybridization studies confirmed the diagnosis of monophasic spindle cell synovial sarcoma.

It was unclear at presentation if this represented a metastatic or primary pulmonary synovial sarcoma. Due to her pregnancy and possible fetal risk, the patient declined whole body imaging (i.e., PET-CT) to survey for a possible primary source. A repeat comprehensive physical exam failed to reveal any soft tissue masses. Based on these clinical observations and testing, it was assumed that the lung mass was a primary pulmonary synovial sarcoma.

Surgical resection, the only possible immediate cure, was deferred due to pregnancy as well as the size and proximity of the mass to vital structures. Neoadjuvant chemotherapy would necessarily focus on containing the growth of the mass, with hopes of inducing tumor necrosis, without causing undue harm to the fetus. A literature review yielded data supporting clinical benefit and acceptable third-trimester fetal risk associated with ifosfamide [7-9]. She was given 2 cycles of ifosfamide as follows: $2 \mathrm{~g} / \mathrm{m}^{2}$ IV bolus over $4 \mathrm{~h}$ followed by $2 \mathrm{~g} / \mathrm{m}^{2} /$ day as continuous IV infusions for 6 days (the total dose given was $14 \mathrm{~g} / \mathrm{m}^{2} /$ cycle) each along with mesna. These were initiated at 26 and 29 weeks' gestation.

At 31 weeks' gestation, the patient reported deceased fetal movements. Her obstetrician discovered oligohydramnios and a non-reassuring fetal tracing. The patient was then rushed to the operating room for an emergency $\mathrm{C}$-section. She delivered a baby boy, who, aside from typical prematurity-associated concerns, was healthy. The patient's follow-up chest CT after delivery showed approximately $30 \%$ decrease in the size of the primary mass (fig. 3a, b).

After delivery, the patient was treated with two more cycles of standard neoadjuvant chemotherapy with mesna, adriamycin, and ifosfamide. She also underwent a PET-CT, which 
showed increased metabolic activity solely at the site of the known lung malignancy and an estimated 30\% decrease in the size of the primary mass. She was then scheduled for right total pneumonectomy and mediastinal lymphadenectomy approximately 8 weeks after the birth of her son. Gross pathology revealed a large, white-tan, necrotic tumor mass in the right upper lobe extending inferiorly down into the interlobar fissure. Histology confirmed the primary diagnosis of synovial sarcoma, with evidence of necrosis. All 5 resected lymph nodes as well as the bronchial and vascular margins were free of tumor. Adjuvant mesna, adriamycin, and ifosfamide were offered, but the patient declined due to concerns about toxicity.

A PET-CT scan performed 5 months later revealed recurrent sarcoma and a $4.7-\mathrm{cm}$ right hilar and hypermetabolic mass compressing the right main pulmonary artery and indenting the left atrium. There was no evidence of metastatic disease. Bronchoscopy with endobronchial ultrasound delineated a right hilar/paratracheal mass $3-4 \mathrm{~cm}$ in size, causing extrinsic compression of the left mainstem bronchus. Palliative radiation therapy was then given $(3,750$ cGY over 15 days). The patient developed fistulae involving the trachea, bronchus, pleura, and esophagus, followed by cardiomyopathy and pneumonia. She eventually succumbed to her disease and passed away approximately 13 months after her diagnosis.

\section{Discussion}

Primary pulmonary sarcomas accounted for approximately $0.2 \%$ of all lung cancers in the USA between 1975 and 2007 [10]. Synovial sarcoma is a subset of the soft tissue sarcomas with unknown histological origin. Immunohistochemistry can be helpful in diagnosis, but due to the variability in surface antigen expression, demonstration of the $\mathrm{t}(\mathrm{X} ; 18)(\mathrm{p} 11.2 ; \mathrm{q} 11.2)$ is critical as a confirmatory test as it is present in $95 \%$ of all synovial sarcomas [11].

The diagnosis of cancer occurs once in every 1,000 pregnancies, with breast, uterine, and cervical cancer, lymphoma, and melanoma being the most common [12]. To date, only two primary synovial sarcomas discovered during pregnancy have been reported. The first case was reported by Sakurai et al. [6] in 2006 and describes a 33-year-old female who presented with acute back pain and a left hemothorax in her fifth month of pregnancy. She subsequently underwent surgical evacuation of the hemothorax and resection of the tumor. She opted to have an abortion and declined further treatment in 2008. Esaka et al. [5] reported the case of a young woman in the 34th week of gestation who presented with a pneumothorax. Since the patient was close to term, delivery was induced, allowing for expedited pneumonectomy and adjuvant chemotherapy. However, the patient died 13 months after resection.

Most synovial sarcomas arise in the extremities and have a predilection to metastasize to the lung [12]. Thus, when this neoplasm is found in the lung, a thorough evaluation for a remote primary lesion is needed. This presents a challenge during pregnancy since standard whole-body imaging modalities are potentially harmful to the fetus. This necessitated the reliance on a thorough physical exam for a primary lesion, which was not found. Postnatal PET scans confirmed no suspicious lesions as well. Complete surgical resection of the primary tumor, in this case via a right pneumonectomy, was also contraindicated due to pregnancy.

To our knowledge, this is the first case of a pregnant patient with primary pulmonary synovial sarcoma treated with chemotherapy. 


\section{Case Reports in Oncology}

\begin{tabular}{l|l}
\hline Case Rep Oncol 2014;7:139-143 \\
\hline DOI: $10.1159 / 000360522$ & $\begin{array}{l}\text { (c) 2014 S. Karger AG, Basel } \\
\text { www.karger.com/cro }\end{array}$ \\
\hline
\end{tabular}

Harris et al.: Primary Pulmonary Synovial Sarcoma during Pregnancy: A Diagnostic and Therapeutic Dilemma

\section{References}

1 Weiss SW, Goldblum JR: Enzinger and Weiss's Soft Tissue Tumors. St Louis, Mosby, 2008, pp 1161-1182. Pai S, Chinoy RF, Pradhan SA, et al: Head and neck synovial sarcomas. J Surg Oncol 1993;54:82-86. Fetsch JF, Meis JM: Synovial sarcoma of the abdominal wall. Cancer 1993;72:469-477.

4 Begueret H, Galateau-Salle F, Guillou L, et al: Primary intrathoracic synovial sarcoma: a clinicopathologic study of $40 \mathrm{t}(\mathrm{X} ; 18)$-positive cases from the French Sarcoma Group and the Mesopath Group. Am J Surg Pathol 2005;29:339-346.

5 Esaka EJ, Celebrezze JU, Golde SH, Chiossi G, Thomas RL: Pulmonary synovial sarcoma presenting as a pneumothorax during pregnancy. Obstet Gynecol 2008;111:555-558.

-6 Sakurai H, Hosokawa H, Hada M, et al: Spontaneous hemothorax caused by intrathoracic synovial sarcoma. Jpn J Thorac Cardiovasc Surg 2006;54:217-220.

7 Rosen G, Forscher C, Lowebraun S, et al: Synovial sarcoma: uniform response of metastases to high dose ifofsamide. Cancer 1994;73: 2506-2511.

8 Ishii T, Tatezaki S, Satoh T, et al: The effects of high-dose ifofsamide in the treatment of bone and soft tissue sarcomas (in Japanese). Gan To Kagaku Ryoho 1997;24: 2123-2130.

-9 Merimsky 0, Le Cesne A: Soft tissue and bone sarcomas in association with pregnancy. Acta Oncol 1998;37:721-727.

10 Altekruse SF, Kosary CL, Krapcho M, Neyman N, Aminou R, Waldron W, Ruhl J, Howlader N, Tatalovich Z, Cho H, Mariotto A, Eisner MP, Lewis DR, Cronin K, Chen HS, Feuer EJ, Stinchcomb DG, Edwards BK (eds): SEER Cancer Statistics Review, 1975-2007, National Cancer Institute. Bethesda, MD, http://seer.cancer.gov/csr/1975_2007/ (table 15.28), based on November 2009 SEER data submission, posted to the SEER web site, 2010.

11 Coindre JM, Pelmus M, Hostein I, et al: Should molecular testing be required for diagnosing synovial sarcoma? A prospective study of 204 cases. Cancer 2003:15;98: 2700-2707.

12 Garrido M, Clavero J, Huete A, et al: Prolonged survival of a woman with lung cancer diagnosed and treated with chemotherapy during pregnancy. Review of cases reported. Lung Cancer 2008;60:285-290.

E13 Eilber FC, Dry SM: Diagnosis and management of synovial sarcoma. J Surg Oncology 2008;97:314-320.

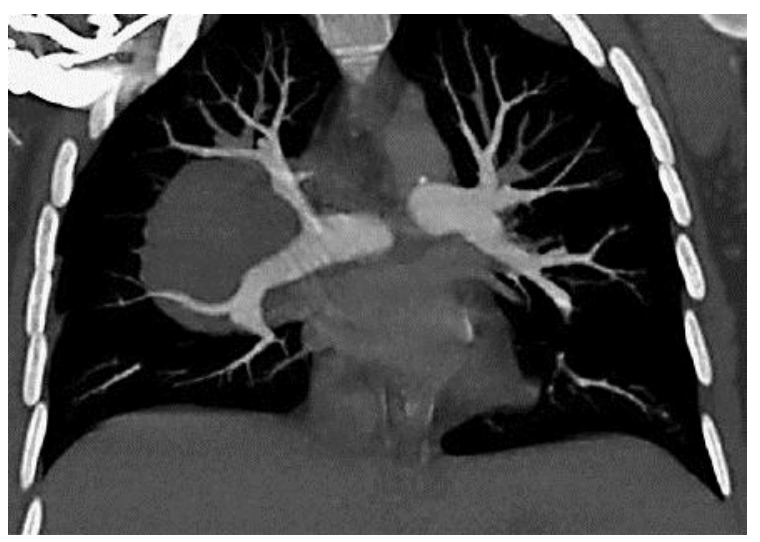

Fig. 1. Coronal view of the chest CT showing a large right hilar mass. 


\section{Case Reports in Oncology}

\begin{tabular}{l|l}
\hline Case Rep Oncol 2014;7:139-143 & \\
\hline DOI: 10.1159/000360522 & $\begin{array}{l}\text { ○ 2014 S. Karger AG, Basel } \\
\text { www.karger.com/cro }\end{array}$ \\
\hline
\end{tabular}

Harris et al.: Primary Pulmonary Synovial Sarcoma during Pregnancy: A Diagnostic and Therapeutic Dilemma

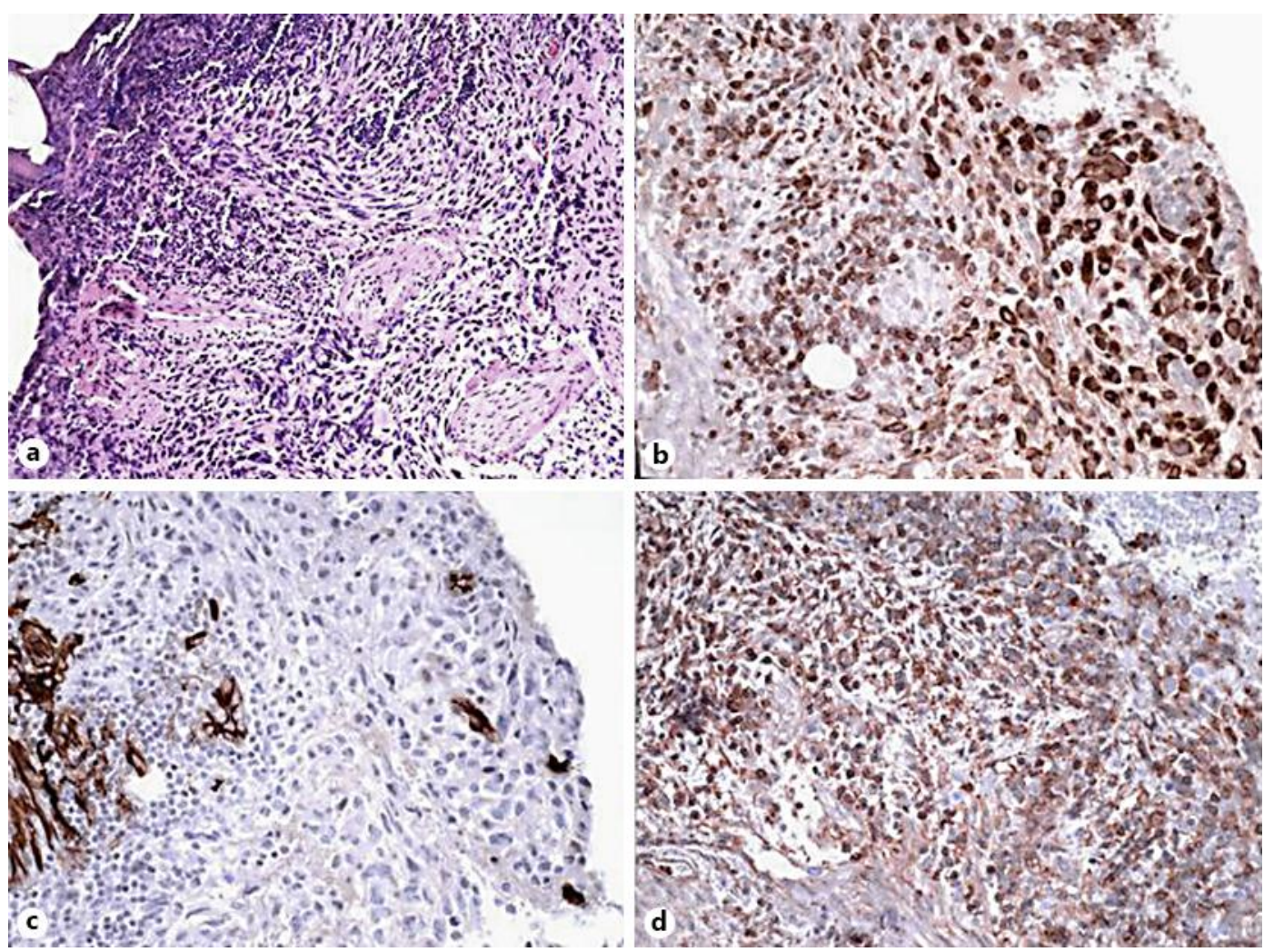

Fig. 2. a H\&E staining of a transbronchial specimen revealing broad, sweeping densely cellular fascicles of spindle cell neoplasm infiltrating endobronchial tissue. b Positive IHC staining for Bcl-2. c Negative IHC staining for CD34. d Positive IHC staining for CD99.
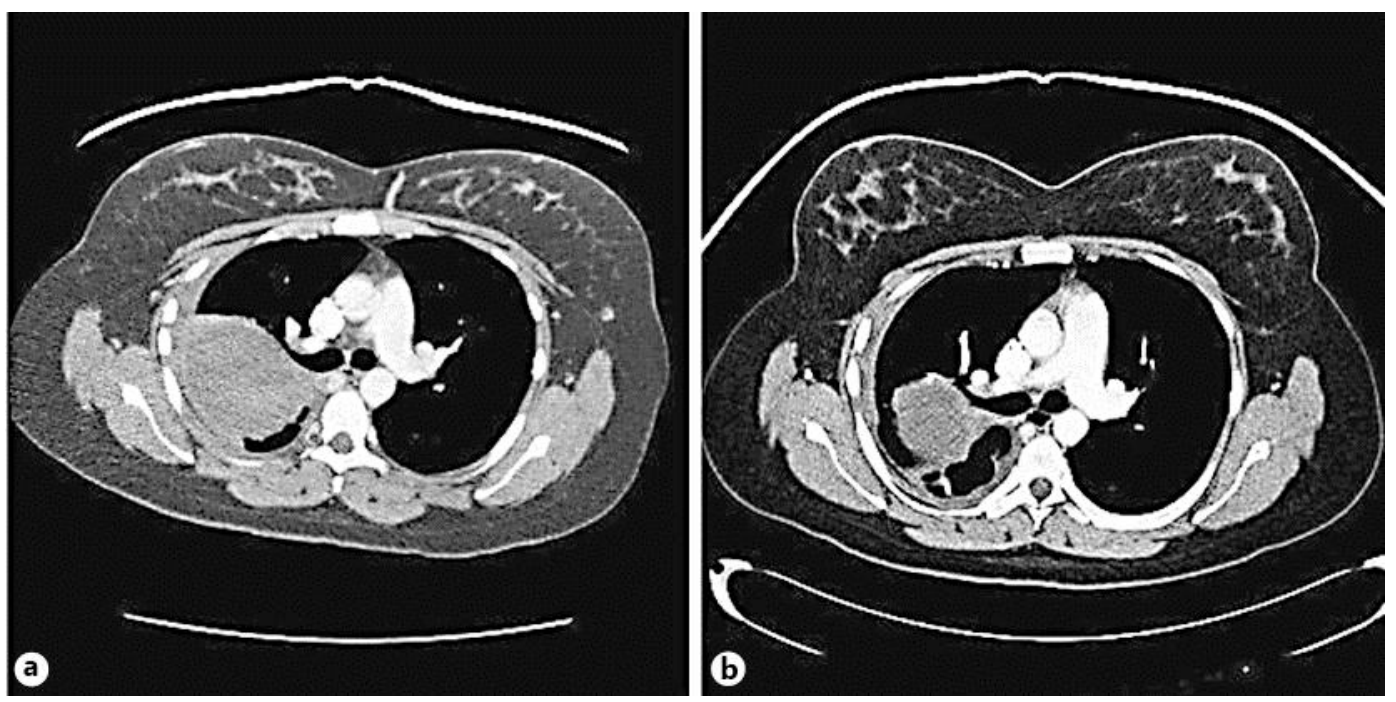

Fig. 3. a axial view of the right hilar mass prior to treatment. b Axial view of the right hilar mass after 2 cycles of ifosfamide. 